\title{
Marmesin-mediated suppression of VEGF/VEGFR and integrin $\beta 1$ expression: Its implication in non-small cell lung cancer cell responses and tumor angiogenesis
}

\author{
JAE HYEON KIM ${ }^{1}$, MIN SU KIM ${ }^{1}$, BO HEE LEE ${ }^{1}$, JIN-KYU KIM ${ }^{2}$, EUN-KYUNG AHN ${ }^{2}$, HYE-JIN KO ${ }^{2}$, \\ YOUNG-RAK $\mathrm{CHO}^{2}$, SANG-JIN LEE ${ }^{3}$, GYU-UN BAE ${ }^{3}$, YONG KEE KIM ${ }^{3}$, \\ JOA SUB $\mathrm{OH}^{1}$ and DONG-WAN SEO ${ }^{1}$ \\ ${ }^{1}$ College of Pharmacy, Dankook University, Cheonan 31116; ${ }^{2}$ Biocenter, Gyeonggi Institute of Science and \\ Technology Promotion, Suwon 16229; ${ }^{3}$ Research Center for Cell Fate Control, College of Pharmacy, \\ Sookmyung Women's University, Seoul 04310, Republic of Korea
}

Received May 19, 2016; Accepted June 29, 2016

DOI: $10.3892 /$ or.2016.5245

\begin{abstract}
In the present study, we investigated the effects and molecular mechanism of marmesin, a natural coumarin compound isolated from Broussonetia kazinoki, on non-small cell lung cancer (NSCLC) cell responses and tumor angiogenesis. Marmesin abrogated mitogen-stimulated proliferation and invasion in both p53 wild-type A549 and p53-deficient H1299 NSCLC cells. These antitumor activities of marmesin were mediated by the inactivation of mitogenic signaling pathways and downregulation of cell signaling-related proteins including vascular endothelial growth factor receptor-2 (VEGFR-2), integrin $\beta 1$, integrin-linked kinase and matrix metalloproteinases-2. Furthermore, marmesin suppressed the expression and secretion of VEGF in both NSCLC cells, leading to inhibition of capillary-like structure formation in human umbilical vein endothelial cells. Collectively, these findings demonstrate the pharmacological roles and molecular targets of marmesin in regulating NSCLC cell responses and tumor angiogenesis.
\end{abstract}

\section{Introduction}

Non-small cell lung cancer (NSCLC) is the most common type of lung cancer and the 5-year relative survival rate is less than $20 \%(1,2)$. Dysregulated activation of receptor tyrosine kinases (RTKs) and their downstream signaling molecules is closely associated with NSCLC growth and progression. Among RTKs, epidermal growth factor receptor (EGFR) is highly expressed or constitutively activated in NSCLC patients with poor prognosis (3), suggesting the rational strategy and

Correspondence to: Professor Dong-Wan Seo, Department of Pharmacy, College of Pharmacy, Dankook University, 119 Dandae-ro, Cheonan 31116, Republic of Korea

E-mail: dwseomb@dankook.ac.kr

Key words: marmesin, non-small cell lung cancer, VEGFR-2, VEGF, integrin $\beta 1$ pharmacological efficacy of EGFR-targeted therapeutics in the treatment of NSCLC. However, inhibition of RTKs including EGFR in the clinic often leads to recurrent and metastatic phenotypes of NSCLC. In addition, anti-angiogenic therapy such as inhibition of vascular endothelial growth factor-A (VEGF-A)/VEGF receptor-2 (VEGFR-2) signaling pathways shows a transient therapeutic effect and subsequent development of NSCLC resistance (4-6). Thus, a further understanding of the molecular mechanism of RTK-mediated signaling pathways in NSCLC growth and progression in the tumor microenvironment is a prerequisite for the identification of therapeutic targets and the development of highly effective anticancer drugs.

Broussonetia kazinoki (B. kazinoki) has been used as a traditional medicine for the treatment of blurred vision and inflammatory and infectious diseases as well as a raw material for paper production in Northeastern Asia including Korea. Previous investigations have demonstrated that B. kazinoki extract and its bioactive components such as flavan derivatives have anti-diabetic, anti-allergic, anti-inflammatory and antitumor properties (7-12). We recently reported that an ethanolic extract of B. kazinoki and marmesin regulate VEGF-A-induced endothelial cell fates in vitro and angiogenic sprouting exvivo $(13,14)$. Marmesin, a furanocoumarin component isolated from a variety of plants including Peucedanum japonicum, Dystaenia takeshimana, Feronia limonia and Ferula lutea as well as B. kazinoki, has been reported to exert a variety of pharmacological functions such as anti-inflammatory, antihepatotoxic, anti-angiogenic and antitumor activities (14-18). However, the effects and molecular mechanisms of marmesin on NSCLC cell responses have never been elucidated, to date. In the present study, we report for the first time the regulatory effects and molecular mechanisms of marmesin on NSCLC cell fates and tumor-derived angiogenic responses.

\section{Materials and methods}

Cell culture conditions. Human NSCLC cell lines (A549 and H1299) were obtained from the American Type Culture 
Collection (ATCC; Manassas, VA, USA) and were grown in $10 \%$ fetal bovine serum-Dulbecco's modified Eagle's medium (FBS-DMEM) (HyClone Laboratories, Logan, UT, USA). Human umbilical vein endothelial cells (HUVECs) were purchased from Lonza (Walkersville, MD, USA) and used between passages 4 and 6 for all experiments. Cells were cultured in EGM- $2^{\circledR}$ BulletKit media, according to the manufacturer's instructions (Lonza).

Reagents. Marmesin was isolated in an ethyl acetate fraction partitioned from the ethanolic extract of $B$. kazinoki. The following pharmacological agents and antibodies were purchased from commercial sources: anti-phospho-Src (Y416), anti-Src, anti-phospho-MEK (S217/S221), anti-MEK, anti-phospho-ERK (T202/Y204), anti-phospho-Akt (S473), anti-phospho-p70 ${ }^{\mathrm{S} 6 \mathrm{~K}}$ (T421/S424) and phospho-pRb (S780) (Cell Signaling Technology, Beverly, MA, USA); anti-ERK, anti-Akt, anti-p70 ${ }^{\mathrm{S} 6 \mathrm{~K}}$, anti-VEGFR-2, anti-integrin $\alpha 3$, anti-integrin $\beta 1$, anti-ILK, anti-Cdk4, anti-Cdk2, anti-actin antibodies, and mouse and rabbit IgG-horseradish peroxidase conjugates (Santa Cruz Biotechnology, Santa Cruz, CA, USA).

Cell viability and proliferation assay. Subconfluent A549 and H1299 cells, plated on 6-well plates ( $5 \times 10^{4}$ cells/well; SPL Life Sciences, Gyeonggi-do, Korea), were serum-starved for $24 \mathrm{~h}$ in basal DMEM to synchronize cells in the $G_{1} / G_{0}$ phase of the cell cycle, and pretreated with marmesin $(0.1-10 \mu \mathrm{M})$ for $30 \mathrm{~min}$ prior to $10 \% \mathrm{FBS}$ stimulation for $24 \mathrm{~h}$. In some experiments, quiescent cells were pretreated with marmesin $(10 \mu \mathrm{M})$ for $30 \mathrm{~min}$, followed by $10 \%$ FBS stimulation for $12 \mathrm{~h}$. After stimulation, cells were thoroughly rinsed with phosphate-buffered saline (PBS; $\mathrm{pH}$ 7.4) to remove any residual marmesin, and further incubated with $10 \%$ FBS for another $12 \mathrm{~h}$ until the end of the $24 \mathrm{~h}$ time point. Cell viability was determined by a Muse $^{\mathrm{TM}}$ Cell Analyzer using cell count and viability assay kit (Merck Millipore, Billerica, MA, USA), and the cell proliferation was quantified as previously described (19). The results from triplicate determinations (mean \pm standard deviation) are presented as the percentage of viable cells of total cell count or the fold-increase of the untreated controls.

Western blot analysis. Quiescent cells were pretreated with marmesin for $30 \mathrm{~min}$, followed by $10 \%$ FBS stimulation for different time points, as indicated. Cells were rinsed twice with ice-cold PBS and lysed by incubation in $50 \mathrm{mM}$ Tris- $\mathrm{HCl}$ (pH 7.4), $150 \mathrm{mM} \mathrm{NaCl,} 10 \%$ glycerol, $1 \%$ Triton $\mathrm{X}-100$, $1 \mathrm{mM}$ EDTA, $100 \mu \mathrm{g} / \mathrm{ml}$ AEBSF, $10 \mu \mathrm{g} / \mathrm{ml}$ aprotinin, $1 \mu \mathrm{g} / \mathrm{ml}$ pepstatin A, $0.5 \mu \mathrm{g} / \mathrm{ml}$ leupeptin, $80 \mathrm{mM} \beta$-glycerophosphate, $25 \mathrm{mM}$ sodium fluoride and $1 \mathrm{mM}$ sodium orthovanadate for $30 \mathrm{~min}$ at $4^{\circ} \mathrm{C}$. Cell lysates were clarified at $13,000 \mathrm{x} \mathrm{g}$ for $20 \mathrm{~min}$ at $4^{\circ} \mathrm{C}$, and the supernatants were subjected to western blotting as previously described (20). All western blot analyses are representative of at least three independent experiments. Bands of interest were integrated and quantified by the use of National Institutes of Health (NIH) ImageJ version $1.34 \mathrm{~s}$ software.

Cell invasion assay. The upper side of the Transwell insert (6.5-mm diameter insert, $8-\mu \mathrm{m}$ pore size) (Corning Costar, Inc., Corning, NY, USA) was coated with $50 \mu \mathrm{l}$ of $1 \mathrm{mg} / \mathrm{ml}$
Matrigel $^{\circledR}$ (BD Biosciences, Bedford, MA, USA) diluted in serum-free DMEM. Aliquots $(100 \mu \mathrm{l})$ of cells $\left(5 \times 10^{5}\right.$ cells $\left./ \mathrm{ml}\right)$ resuspended in serum-free DMEM were added to the upper compartment of the Matrigel-coated Transwell and $600 \mu \mathrm{l}$ of serum-free DMEM was added to the lower compartment. After serum starvation for $2 \mathrm{~h}$, the cells were pretreated with marmesin $(10 \mu \mathrm{M})$ for $30 \mathrm{~min}$, followed by $10 \%$ FBS stimulation for $16 \mathrm{~h}$. The inserts were fixed with methanol and using a cotton-tipped swab the non-invasive cells were removed from the top of the membrane. After staining with $0.04 \%$ Giemsa staining solution (Sigma-Aldrich Co., St. Louis, MO, USA), the numbers of invasive cells (mean \pm standard deviation) were determined from six different fields using $\mathrm{x} 200$ objective magnification $(21,22)$.

RNA purification and reverse transcriptase-polymerase chain reaction. Total RNA was purified with PureHelix ${ }^{\mathrm{TM}}$ RNA extraction solution (Nanohelix Co., Daejeon, Korea). Integrity of RNA was checked by agarose gel electrophoresis and ethidium bromide staining. One microgram of RNA was used as template for each reverse transcriptase (RT)-mediated polymerase chain reaction (PCR) using First Strand cDNA Synthesis kit (BioAssay Co., Ltd., Daejeon, Korea). Primers for PCR were synthesized by Bioneer Corporation (Daejeon, Korea). Primer sequences were as follows: MMP-2 forward, 5'-GCTCAGATCCGTGGTGAGAT-3' and reverse, 5'-GGTG CTGGCTGAGTAGATCC-3'; VEGFR-2 forward, 5'-TGCCT ACCTCACCTGTTTCCT-3' and reverse, 5'-TACACGGTGG TGTCTGTGTCA-3'; VEGF-A forward, 5'-TCGGGCCTCCG AAACCATGA-3' and reverse, 5'-CCTGGTGAGAGATCTG GTTC-3'; glyceraldehyde-3-phosphate dehydrogenase (GAPDH) forward, 5'-GAAGGTGAAGGTCGGAGTC-3' and reverse, 5'-GAAGATGGTGATGGGATTTC-3'. Bands of interest were integrated and quantified by the use of NIH Image J version $1.34 \mathrm{~s}$ software.

VEGF enzyme-linked immunosorbent assay (ELISA). Quiescent cells were pretreated with marmesin $(10 \mu \mathrm{M})$ for $30 \mathrm{~min}$, followed by $10 \%$ FBS stimulation for $12 \mathrm{~h}$. Cells were washed with PBS to remove any residual marmesin, and then further stimulated with $10 \%$ FBS for another $12 \mathrm{~h}$. ELISA assay was performed to measure the concentration of VEGF in the conditioned media using VEGF ELISA kit (R\&D Systems, Minneapolis, MN, USA), according to the manufacturer's instructions. Secreted VEGF levels were analyzed at $450 \mathrm{~nm}$ using BioTek Synergy Mx microplate reader (BioTek Instruments, Winooski, VT, USA).

Tube formation assay. Tube formation assay was performed to examine the ability of conditioned media from marmesin-treated NSCLC cells to regulate angiogenic responses in vitro. Quiescent NSCLC cells were pretreated with marmesin $(10 \mu \mathrm{M})$ for $30 \mathrm{~min}$, followed by $10 \% \mathrm{FBS}$ stimulation for $12 \mathrm{~h}$. Cells were washed with PBS to remove any residual marmesin, and then further stimulated with $10 \%$ FBS for another $12 \mathrm{~h}$. After stimulation, conditioned media were collected. Quiescent HUVECs $\left(4 \times 10^{4}\right.$ cells $\left./ \mathrm{ml}\right)$ were added to Matrigel ${ }^{\circledR}$-coated plates and treated with conditioned media for $9 \mathrm{~h}$. Tube formation was observed with an Olympus CKX41 inverted microscope (CAchN 10/0.25php objective) 
A
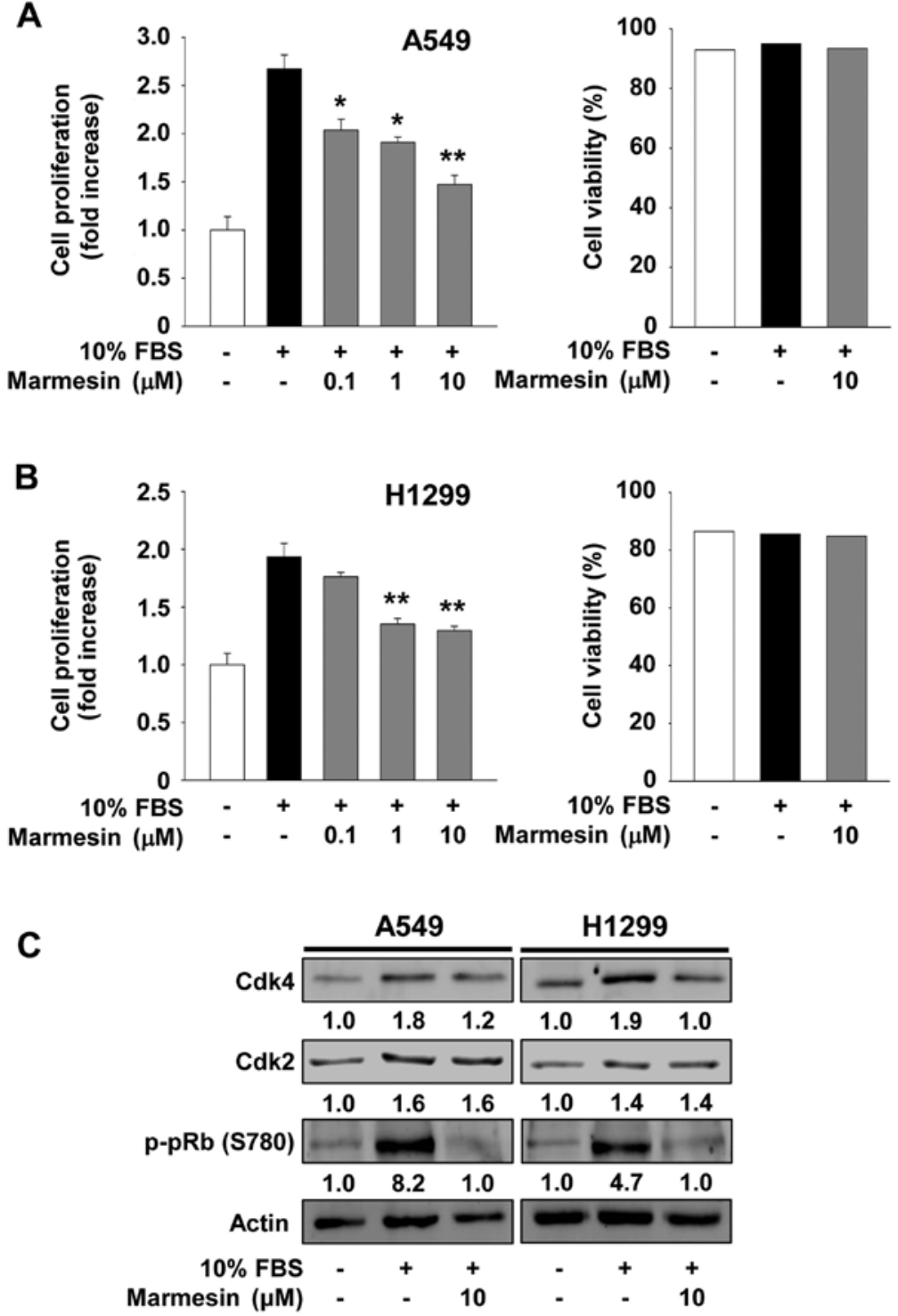

Figure 1. Effects of marmesin on cell proliferation and viability in NSCLC cells. Quiescent A549 and H1299 cells were pretreated with marmesin (0.1-10 $\mu \mathrm{M})$ for $30 \mathrm{~min}$, followed by $10 \% \mathrm{FBS}$ stimulation for $24 \mathrm{~h}$. (A and B) Cell proliferation (left panel), viability (right panel) and (C) western blot analyses were performed as described in Materials and methods. The results from at least three independent experiments (mean \pm SD) are presented as the fold-increase of the untreated controls (for proliferation) or the percentage of the viable cells of the total cell counts (for viability). Statistical significance is indicated $\left({ }^{*} \mathrm{P}<0.05\right.$, ${ }^{* *} \mathrm{P}<0.01$, compared with $10 \%$ FBS-treated cells). (C) Cell lysates were subjected to western blot analysis with anti-Cdk4, anti-Cdk2, anti-phospho-pRb (S780) or antiactin antibodies. Integrated density values were normalized to the untreated controls.

and ToupTek Toupview software (version x36, 3.5.563; Hangzhou ToupTek Photonics Co., Zhejiang, China).

Statistical analysis. Statistical analysis was performed using Student's t-test, and was based on at least three different experiments. The results were considered to be statistically significant at $\mathrm{P}<0.05$.

\section{Results}

Marmesin inhibits NSCLC cell proliferation. We first investigated the ability of marmesin to regulate cell proliferation in p53 wild-type A549 and p53-deficient H1299 NSCLC cells (Fig. 1A and B). Marmesin treatment inhibited mitogen-stimulated cell proliferation in a dose-dependent manner and did not alter cell viability and morphology at the highest concentration used in the present study, indicating that marmesin-mediated inhibition of cell proliferation was not mediated by induction of apoptosis or cytotoxicity. Based on these findings, we next analyzed the changes in the cell cycle regulatory proteins in the marmesin-treated NSCLC cells (Fig. 1C). Marmesin treatment markedly suppressed mitogen-induced expression of cyclin-dependent kinase 4 (Cdk4), but not $\mathrm{Cdk} 2$, to levels observed in the untreated controls, resulting in inhibition of $\mathrm{pRb}$ phosphorylation in both NSCLC cell lines. Marmesin has previously been reported to inhibit proliferation by downregulation of $\mathrm{Cdk} 4, \mathrm{Cdk} 2$ and cyclin D in VEGF-A-treated HUVECs (14). Although the molecular mechanism of marmesin in regulating cell cyclerelated proteins appears slightly different in cell types, these findings demonstrate the antiproliferative activity of marmesin against various types of cells, independently of p53 expres- 
A
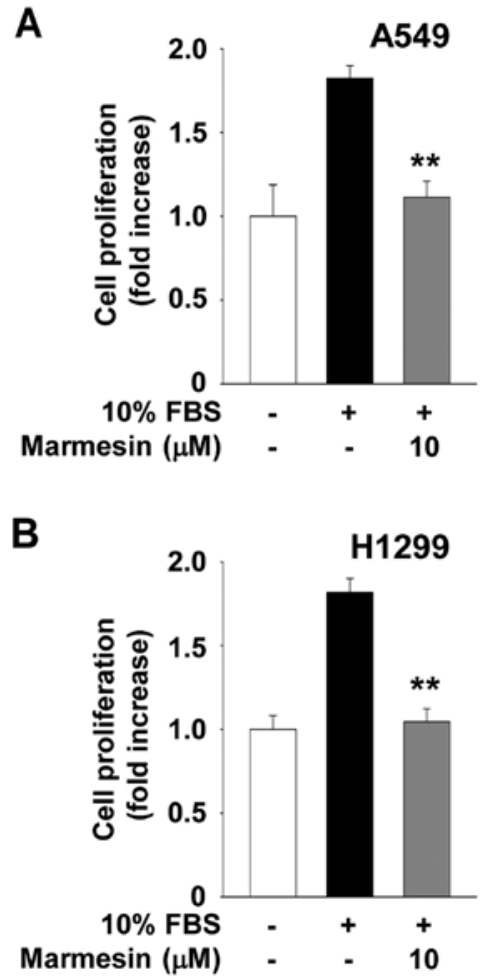

Figure 2. Irreversible effect of marmesin on cell proliferation in NSCLC cells. Quiescent (A) A549 and (B) H1299 cells were pretreated with marmesin $(10 \mu \mathrm{M})$ for $30 \mathrm{~min}$, followed by $10 \%$ FBS stimulation for $12 \mathrm{~h}$. Following stimulation, cells were washed thoroughly with PBS to remove any residual marmesin, and further incubated with 10\% FBS for another $12 \mathrm{~h}$ until the end of the $24 \mathrm{~h}$ time point. The results from at least three independent experiments (mean $\pm \mathrm{SD}$ ) are presented as the fold-increase of the untreated controls. Statistical significance is indicated $\left({ }^{* *} \mathrm{P}<0.01\right.$, compared with the 10\% FBS-treated cells).

sion status. In addition, the inhibitory effect of marmesin on NSCLC cell proliferation was not changed after the withdrawal of marmesin at the $12 \mathrm{~h}$ time point, and was sustained up to $24 \mathrm{~h}$, suggesting that this effect may be irreversible until the end of this experiment (Fig. 2).

Marmesin inhibits NSCLC cell invasion. We next examined the effect of marmesin on cell invasion in the A549 and H1299 cells. Marmesin treatment markedly blocked mitogen-stimulated cell invasion (Fig. 3A and B). The regulatory pattern of marmesin on NSCLC cell invasion was very similar to that on NSCLC cell migration (data not shown). Based on these findings, we analyzed the changes in expression of matrix metalloproteinases (MMPs) in the marmesin-treated NSCLC cells. Expression and activity of MMPs have been known to modulate cell migration, invasion and angiogenesis by degrading extracellular matrix components and cell surface molecules (23-26). As shown in Fig. 3C, marmesin treatment suppressed mitogen-induced expression of MMP-2 in both cell lines. In contrast, the levels of tissue inhibitor of metalloproteinases-2, an endogenous inhibitor of MMPs, were not altered in the mitogen- or marmesin-treated NSCLC cells (data not shown) (27-29). Collectively, these findings suggest that inhibition of cell invasion by marmesin is mediated, at least in part, through the suppression of MMP-2 expression (Fig. 3C).
A

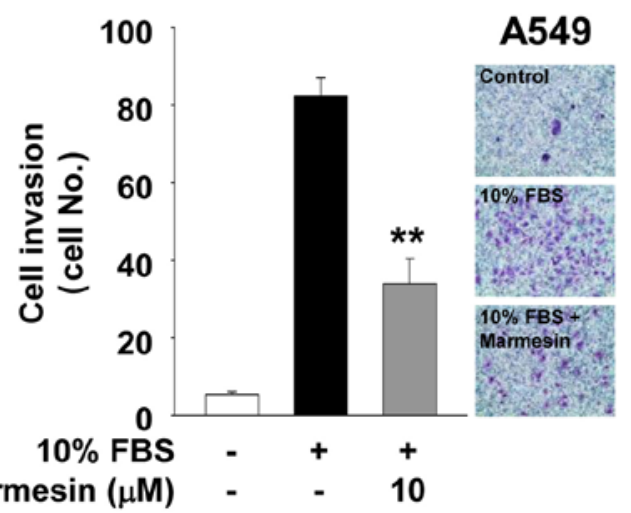

B

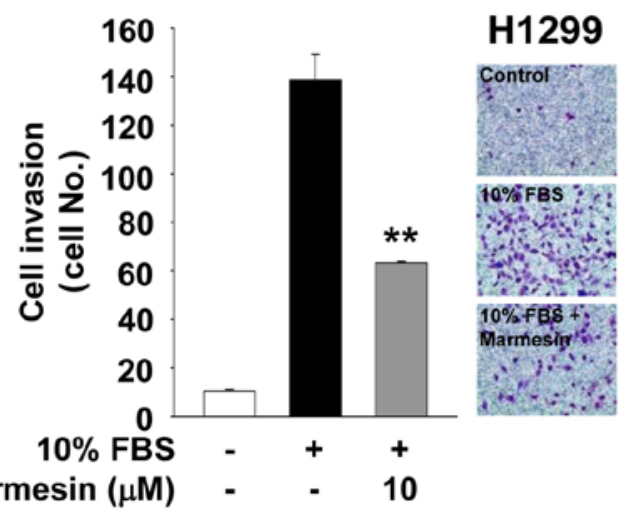

C

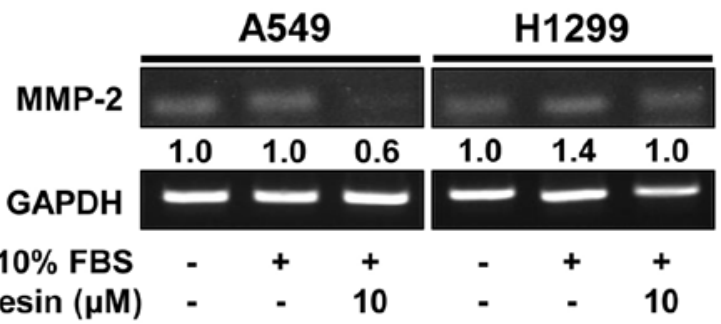

Figure 3. Effects of marmesin on cell invasion and MMP-2 expression in NSCLC cells. (A and B) In vitro Transwell invasion and (C) RT-PCR analyses were performed as described in Materials and methods. (A) A549 and (B) $\mathrm{H} 1299$ cells were pretreated with marmesin $(10 \mu \mathrm{M})$ for $30 \mathrm{~min}$, followed by $10 \%$ FBS stimulation for (A and B) 16 or (C) $24 \mathrm{~h}$. The number of invasive cells was determined by counting six different fields of cells (magnification, $\mathrm{x} 200$ ). Results from six independent experiments (mean \pm SD) are presented as the number of invasive cells. Statistical significance is indicated $\left({ }^{* *} \mathrm{P}<0.01\right.$, compared with $10 \%$ FBS-treated cells). (C) Results shown are representative of at least three independent experiments. Integrated density values were normalized to untreated controls.

Marmesin-mediated inhibition of NSCLC cell proliferation and invasion is mediated through inactivation of mitogenstimulated signaling pathways and downregulation of cell surface signaling molecules. To elucidate the molecular mechanisms and therapeutic targets of marmesin in regulating NSCLC cell proliferation and invasion, we examined the changes in activation of mitogen-stimulated signaling pathways including Src kinase, mitogen-activated protein kinase (MEK), extracellular signal-regulated kinase (ERK), Akt and p70S6 kinase $\left(\mathrm{p} 70^{\mathrm{s} 6 \mathrm{~K}}\right)$ in marmesin-treated NSCLC cells $(14,30)$. As expected, mitogenic stimulation significantly increased the phosphorylation of MEK, ERK, Akt and $\mathrm{p} 70^{\mathrm{s} 6 \mathrm{~K}}$, 


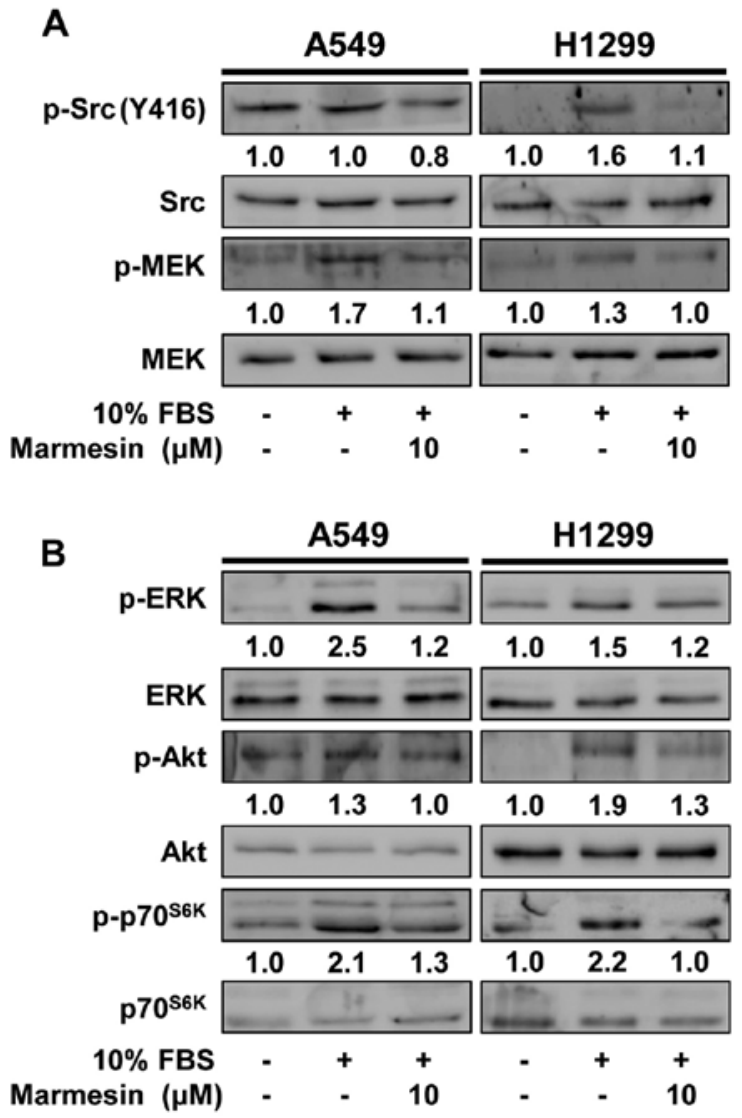

Figure 4. Effect of marmesin on mitogen-stimulated signaling pathways in NSCLC cells. Quiescent NSCLC cells were pretreated with marmesin $(10 \mu \mathrm{M})$ for $30 \mathrm{~min}$, followed by $10 \%$ FBS stimulation for (A) 5 or (B) $15 \mathrm{~min}$. Results shown are representative of at least three independent experiments. Integrated density values were normalized to untreated controls.

as compared with unstimulated controls (Fig. 4). In contrast, marmesin treatment markedly inhibited mitogen-stimulated phosphorylation of Src, MEK, ERK, Akt and p70 ${ }^{\mathrm{S} 6 \mathrm{~K}}$ in both NSCLC cells. Moreover, marmesin treatment markedly suppressed mitogen-induced expression of cell signaling molecules such as VEGFR-2, integrin $\beta 1$ and integrin-linked kinase (ILK), and a key angiogenic factor VEGF, which play important roles in cancer growth and progression associated with angiogenesis (Fig. 5) (31-33). In addition to direct antitumor activity, these findings suggest the possibility that marmesin may regulate angiogenic responses through inhibition of VEGF expression and secretion in NSCLC cells.

Marmesin inhibits endothelial cell tube formation by downregulation of NSCLC-derived VEGF secretion. In the tumor microenvironment cancer cells secrete a variety of biological molecules including cytokines and growth factors, which play important roles in cellular responses such as proliferation, migration, invasion and angiogenesis $(5,34)$. Based on inhibitory effect of marmesin on VEGF expression, we thus analyzed the secreted levels of VEGF in conditioned media collected from marmesin-treated NSCLC cells. As shown in Fig. 6A, marmesin treatment significantly inhibited the secretion of VEGF from both NSCLC cell lines in response
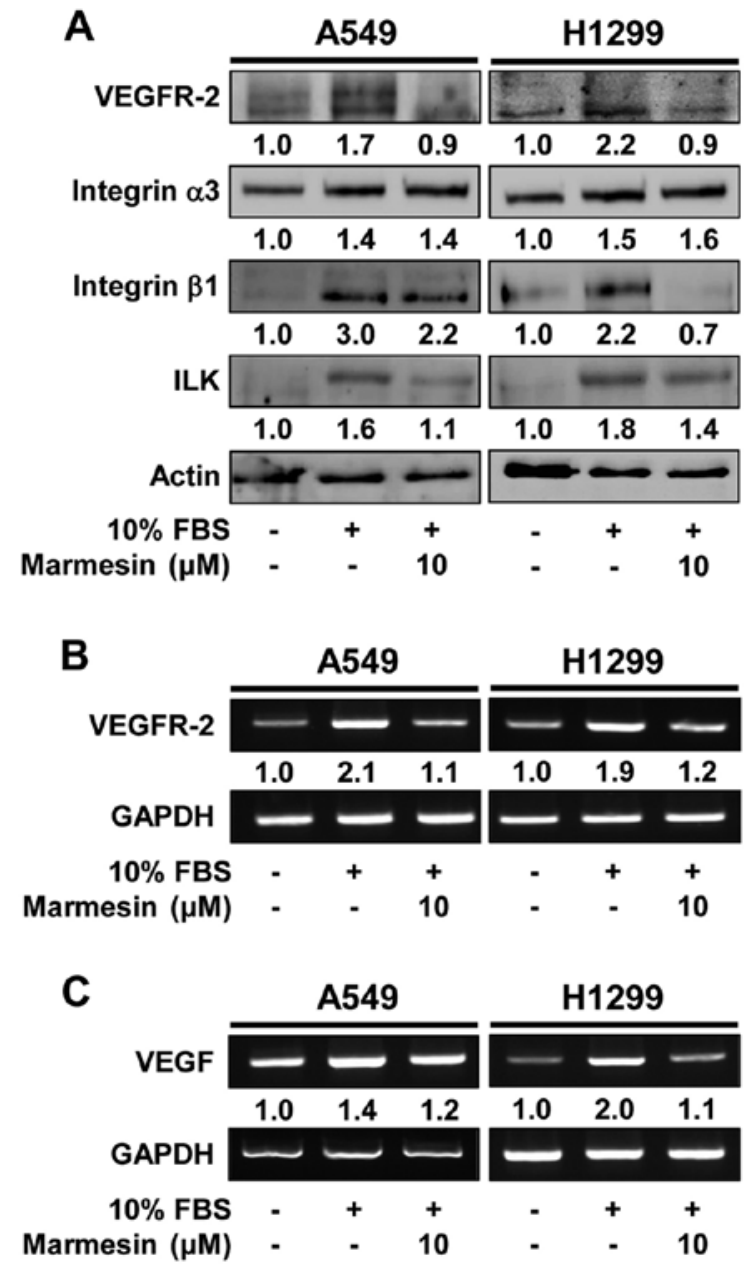

Figure 5. Effect of marmesin on the expression of mitogen-stimulated signaling molecules in NSCLC cells. (A) Western blot and (B and C) RT-PCR analyses were performed as described in Materials and methods. Quiescent NSCLC cells were pretreated with marmesin $(10 \mu \mathrm{M})$ for $30 \mathrm{~min}$, followed by $10 \%$ FBS stimulation for $24 \mathrm{~h}$. Results shown are representative of at least three independent experiments. Integrated density values were normalized to untreated controls.

to mitogenic stimulation. H1299 cells were found to be more responsive to marmesin-mediated inhibition of VEGF secretion, as compared with A549 cells. These findings are similar to the patterns of VEGF transcription levels in marmesintreated NSCLC cells (Fig. 5C), demonstrating that marmesin inhibits VEGF secretion through downregulation of VEGF mRNA expression. To determine whether secreted biomolecules including VEGF from marmesin-treated NSCLC cells affect the cellular fate of adjacent and/or other cells, we next performed in vitro angiogenesis assay using conditioned media from NSCLC cells treated with or without marmesin (Fig. 6B). The conditioned media from marmesin-treated NSCLC cells significantly inhibited the formation of capillary-like structures by HUVECs. Although the types and levels of biomolecules secreted from marmesin-treated NSCLC cells remain to be further identified, these observations suggest that marmesin-mediated inhibition of VEGF expression and secretion in NSCLC cells may be one of the major factors in the modulation of tumor-derived angiogenesis (Fig. 6B). 

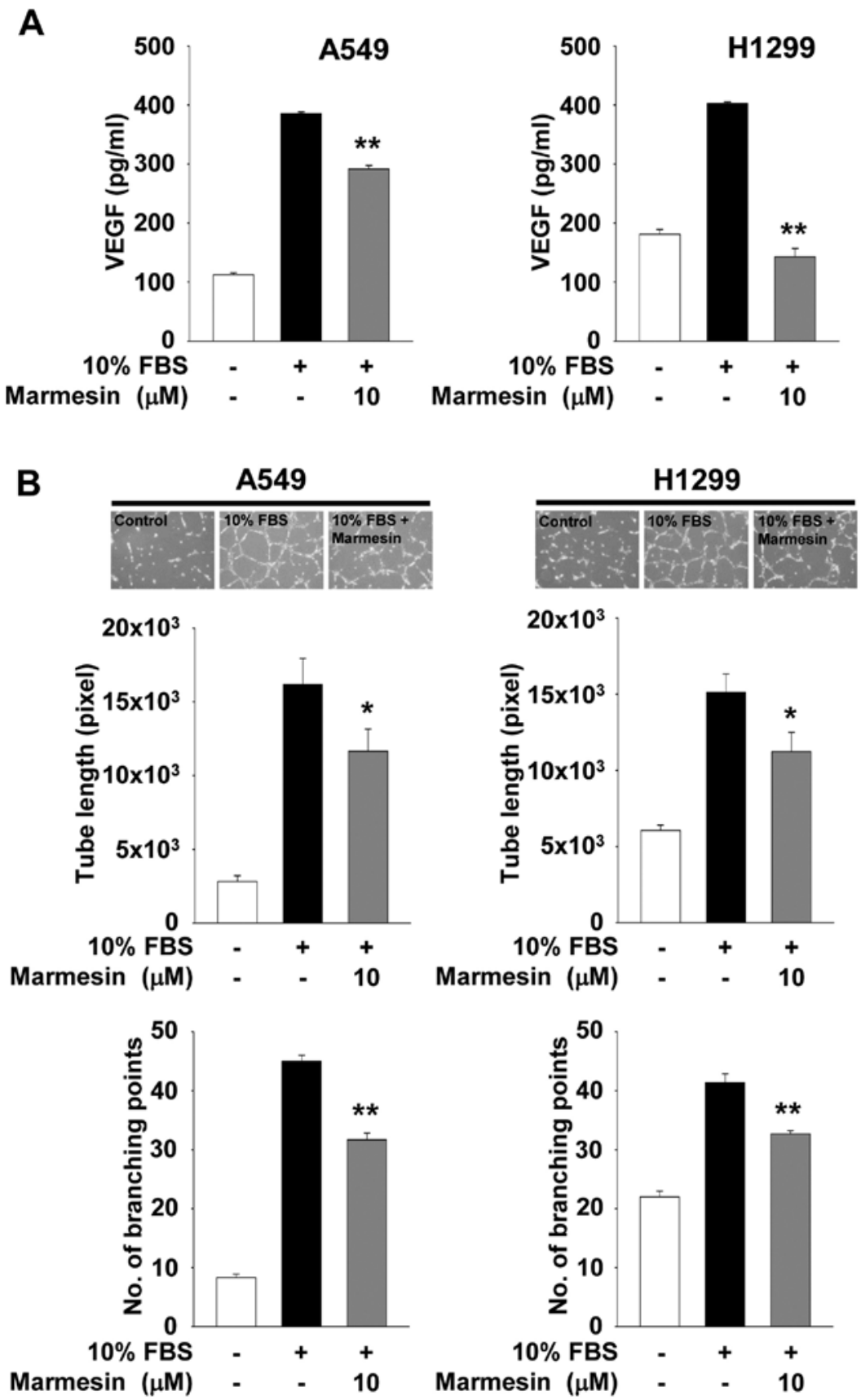

Figure 6. Effects of marmesin on VEGF secretion in NSCLC cells and angiogenic responses in vitro. Quiescent NSCLC cells were pretreated with marmesin $(10 \mu \mathrm{M})$ for $30 \mathrm{~min}$, followed by $10 \%$ FBS stimulation for $12 \mathrm{~h}$. Cells were washed with PBS to remove any residual marmesin, and then further stimulated with $10 \%$ FBS for another $12 \mathrm{~h}$. After stimulation, conditioned media were collected. (A) VEGF ELISA and (B) tube formation assays were performed using conditioned media as described in Materials and methods. Values represent the mean \pm SD of at least three independent experiments. Statistical significance is indicated ( ${ }^{*} \mathrm{P}<0.05,{ }^{* *} \mathrm{P}<0.01$, compared with $10 \%$ FBS-treated cells).

\section{Discussion}

Dysregulated activation of RTKs and/or cross-talk between RTKs and integrins have been known to play important roles in cancer growth, progression and poor prognosis in human lung cancer $(3,4,20,31,34)$. Therefore, highly activated RTKs or integrins are considered as key targets of antitumor agents in clinical trials and use. Numerous investigations indicate that drugs targeting RTKs are more effective than conventional therapeutics for the treatment of lung cancer. However, molecular-targeted therapy in the clinic eventually develops recurrent and metastatic lung cancers, suggesting that the identification of key molecular targets in RTK/integrin signaling pathways is absolutely required for the development of effective therapeutic strategies and agents to treat aggressive types of lung cancer.

Marmesin has been known to exert antitumor activity against several types of cancer cells including colon cancer (18). Recently, we reported that marmesin, a coumarin component isolated from Broussonetia kazinoki, inhibits VEGF-A-induced endothelial cell responses in vitro and angiogenic sprouting ex vivo (14). These findings led us to investigate the effects of 
marmesin on lung cancer cell fate and lung cancer cell-derived angiogenesis. In the present study, we showed that marmesin inhibited proliferation and invasion of NSCLC cells, independently of p53 expression status. Antiproliferative activity of marmesin appeared to be irreversible, since withdrawal of marmesin did not reverse or affect cell proliferation in the NSCLC cells. In addition, marmesin suppressed VEGF expression and secretion in NSCLC cells, leading to inhibition of capillary-like structure formation of HUVECs. The mechanism of these effects involved inactivation of mitogenic signaling pathways such as Src, MEK, ERK, Akt and p70 ${ }^{\mathrm{S} 6 \mathrm{~K}}$, and downregulation of VEGF, VEGFR-2, integrin $\beta 1$, ILK and MMP-2. In conclusion, these findings provide important insights into the regulatory roles and therapeutic potential of marmesin in NSCLC, and warrant preclinical evaluation and development of marmesin as a potent antitumor agent for the treatment of NSCLC associated with pathological angiogenic responses.

\section{Acknowledgements}

The present study was supported by the R\&D Program for Forestry Technology (S121313L070100) through the Korea Forest Service, and by the Basic Science Research Program (2014R1A1A2058015) through the National Research Foundation of Korea, Ministry of Education.

\section{References}

1. Torre LA, Bray F, Siegel RL, Ferlay J, Lortet-Tieulent J and Jemal A: Global cancer statistics, 2012. CA Cancer J Clin 65: 87-108, 2015.

2. Chen Z, Fillmore CM, Hammerman PS, Kim CF and Wong KK: Non-small-cell lung cancers: A heterogeneous set of diseases. Nat Rev Cancer 14: 535-546, 2014.

3. Sharma SV, Bell DW, Settleman J and Haber DA: Epidermal growth factor receptor mutations in lung cancer. Nat Rev Cancer 7: 169-181, 2007.

4. Huang Y and Carbone DP: Mechanisms of and strategies for overcoming resistance to anti-vascular endothelial growth factor therapy in non-small cell lung cancer. Biochim Biophys Acta 1855: 193-201, 2015.

5. Carmeliet $P$ and Jain RK: Principles and mechanisms of vessel normalization for cancer and other angiogenic diseases. Nat Rev Drug Discov 10: 417-427, 2011

6. Ellis LM and Hicklin DJ: VEGF-targeted therapy: Mechanisms of anti-tumour activity. Nat Rev Cancer 8: 579-591, 2008.

7. Cha JY, Kim YT, Kim HS and Cho YS: Antihyperglycemic effect of stem bark powder from paper mulberry (Broussonetia kazinoki Sieb.) in type 2 diabetic Otsuka Long-Evans Tokushima fatty rats. J Med Food 11: 499-505, 2008.

8. Bae UJ, Jang HY, Lim JM, Hua L, Ryu JH and Park BH: Polyphenols isolated from Broussonetia kazinoki prevent cytokine-induced $\beta$-cell damage and the development of type 1 diabetes. Exp Mol Med 47: e160, 2015.

9. Lee JK, Ha H, Lee HY, Park SJ, Jeong SL, Choi YJ and Shin HK: Inhibitory effects of heartwood extracts of Broussonetia kazinoki Sieb on the development of atopic dermatitis in NC/Nga mice. Biosci Biotechnol Biochem 74: 1802-1806, 2010.

10. Ryu JH, Ahn H and Jin Lee H: Inhibition of nitric oxide production on LPS-activated macrophages by kazinol B from Broussonetia kazinoki. Fitoterapia 74: 350-354, 2003.

11. Kim HS, Lim J, Lee DY, Ryu JH and Lim JS: Kazinol C from Broussonetia kazinoki activates AMP-activated protein kinase to induce antitumorigenic effects in HT-29 colon cancer cells. Oncol Rep 33: 223-229, 2015.

12. Jung YC, Han S, Hua L, Ahn YH, Cho H, Lee CJ, Lee H, Cho YY, Ryu JH, Jeon R, et al: Kazinol-E is a specific inhibitor of ERK that suppresses the enrichment of a breast cancer stem-like cell population. Biochem Biophys Res Commun 470: 294-299, 2016.
13. Cho YR, Kim JH, Kim JK, Ahn EK, Ko HJ, In JK, Lee SJ, Bae GU, Kim YK, Oh JS, et al: Broussonetia kazinoki modulates the expression of VEGFR-2 and MMP-2 through the inhibition of ERK, Akt and p70 ${ }^{\mathrm{S} 6 \mathrm{~K}}$-dependent signaling pathways: Its implication in endothelial cell proliferation, migration and tubular formation. Oncol Rep 32: 1531-1536, 2014.

14. Kim JH, Kim JK, Ahn EK, Ko HJ, Cho YR, Lee CH, Kim YK, Bae GU, Oh JS and Seo DW: Marmesin is a novel angiogenesis inhibitor: Regulatory effect and molecular mechanism on endothelial cell fate and angiogenesis. Cancer Lett 369: 323-330, 2015.

15. Chen IS, Chang CT, Sheen WS, Teng CM, Tsai IL, Duh CY and Ko FN: Coumarins and antiplatelet aggregation constituents from formosan Peucedanum japonicum. Phytochemistry 41: $525-530,1996$

16. Kim JS, Kim JC, Shim SH, Lee EJ, Jin W, Bae K, Son KH, Kim HP, Kang SS and Chang HW: Chemical constituents of the root of Dystaenia takeshimana and their anti-inflammatory activity. Arch Pharm Res 29: 617-623, 2006.

17. Jain M, Kapadia R, Jadeja RN, Thounaojam MC, Devkar RV and Mishra SH: Hepatoprotective activity of Feronia limonia root. J Pharm Pharmacol 64: 888-896, 2012.

18. Znati M, Ben Jannet H, Cazaux S, Souchard JP, Harzallah Skhiri F and Bouajila J: Antioxidant, 5-lipoxygenase inhibitory and cytotoxic activities of compounds isolated from the Ferula lutea flowers. Molecules 19: 16959-16975, 2014.

19. In JK, Kim JK, Oh JS and Seo DW: 5-Caffeoylquinic acid inhibits invasion of non-small cell lung cancer cells through the inactivation of $\mathrm{p} 70^{\mathrm{s} 6 \mathrm{~K}}$ and Akt activity: Involvement of $\mathrm{p} 53$ in differential regulation of signaling pathways. Int J Oncol 48: 1907-1912, 2016

20. Yoon HJ, Cho YR, Joo JH and Seo DW: Knockdown of integrin $\alpha 3 \beta 1$ expression induces proliferation and migration of non-small cell lung cancer cells. Oncol Rep 29: 662-668, 2013.

21. Lee HN, Joo JH, Oh JS, Choi SW and Seo DW: Regulatory effects of Siegesbeckia glabrescens on non-small cell lung cancer cell proliferation and invasion. Am J Chin Med 42: 453-463, 2014.

22. Joo JH, Hong SS, Cho YR and Seo DW: 10-Gingerol inhibits proliferation and invasion of MDA-MB-231 breast cancer cells through suppression of Akt and $\mathrm{p} 38^{\mathrm{MAPK}}$ activity. Oncol Rep 35: 779-784, 2016.

23. Bourboulia D and Stetler-Stevenson WG: Matrix metalloproteinases (MMPs) and tissue inhibitors of metalloproteinases (TIMPs): Positive and negative regulators in tumor cell adhesion. Semin Cancer Biol 20: 161-168, 2010.

24. Kessenbrock K, Plaks V and Werb Z: Matrix metalloproteinases: Regulators of the tumor microenvironment. Cell 141: 52-67, 2010.

25. Overall CM and Kleifeld O: Tumour microenvironment - opinion: Validating matrix metalloproteinases as drug targets and anti-targets for cancer therapy. Nat Rev Cancer 6: 227-239, 2006.

26. Vandenbroucke RE and Libert C: Is there new hope for therapeutic matrix metalloproteinase inhibition? Nat Rev Drug Discov 13: 904-927, 2014

27. Seo DW, Li H, Guedez L, Wingfield PT, Diaz T, Salloum R, Wei BY and Stetler-Stevenson WG: TIMP-2 mediated inhibition of angiogenesis: An MMP-independent mechanism. Cell 114: 171-180, 2003.

28. Stetler-Stevenson WG: Tissue inhibitors of metalloproteinases in cell signaling: Metalloproteinase-independent biological activities. Sci Signal 1: re6, 2008.

29. Kim HJ, Cho YR, Kim SH and Seo DW: TIMP-2-derived 18-mer peptide inhibits endothelial cell proliferation and migration through cAMP/PKA-dependent mechanism. Cancer Lett 343: 210-216, 2014.

30. Lemmon MA and Schlessinger J: Cell signaling by receptor tyrosine kinases. Cell 141: 1117-1134, 2010.

31. Desgrosellier JS and Cheresh DA: Integrins in cancer: Biological implications and therapeutic opportunities. Nat Rev Cancer 10: 9-22, 2010.

32. Lee HN, Kim JK, Kim JH, Lee SJ, Ahn EK, Oh JS and Seo DW: A mechanistic study on the anti-cancer activity of ethyl caffeate in human ovarian cancer SKOV-3 cells. Chem Biol Interact 219: 151-158, 2014.

33. Kim SH, Cho YR, Kim HJ, Oh JS, Ahn EK, Ko HJ, Hwang BJ, Lee SJ, Cho Y, Kim YK, et al: Antagonism of VEGF-A-induced increase in vascular permeability by an integrin $\alpha 3 \beta 1-$ Shp-1cAMP/PKA pathway. Blood 120: 4892-4902, 2012.

34. Claesson-Welsh L and Welsh M: VEGFA and tumour angiogenesis. J Intern Med 273: 114-127, 2013. 